\title{
IDENTIFICAÇÃO E MAPEAMENTO DE ÁREAS DE MILHO NA REGIÃO SUL DO BRASIL UTILIZANDO IMAGENS MODIS
}

\author{
JOSÉ L. R. YI ${ }^{1}$, YOSIO E. SHIMABUKURO², JOSÉ A. QUINTANILHA ${ }^{3}$
}

\begin{abstract}
RESUMO: O presente trabalho teve como proposta avaliar a identificação e o mapeamento das áreas de milho da região noroeste do Estado do Rio Grande do Sul a partir de dados multitemporais do sensor MODIS (Moderate Resolution Imaging Spectroradiometer) a bordo do satélite Earth Observing System - EOS-AM (Terra). O algoritmo de classificação supervisionada Spectral Angle Mapper $(S A M)$ foi aplicado com sucesso em uma série multitemporal de imagens EVI préprocessadas. Verificou-se que as áreas classificadas como milho na imagem coincidiam plenamente com áreas mais extensas ou contínuas (>90 ha) de milho. Áreas de menor extensão ou localizadas em encostas de morros, ao lado de vegetação arbórea, não foram detectadas pelo classificador devido à baixa resolução espacial das imagens. A maior utilidade prática da identificação e da classificação digital das áreas de milho obtidas das imagens MODIS está na sua aplicação para isolar ou complementar o mapeamento das áreas agrícolas visando ao seu monitoramento a partir de diferentes índices de vegetação, derivados de imagens de alta resolução temporal e baixa resolução espacial.
\end{abstract}

PALAVRAS-CHAVE: índices de vegetação, classificação supervisionada, sensoriamento remoto orbital.

\section{IDENTIFICATION AND MAPPING OF MAIZE AREAS IN THE SOUTH REGION OF BRAZIL USING MODIS IMAGES}

\begin{abstract}
The present work had the proposal of evaluating the identification and mapping of maize areas in the northwestern region of the State of Rio Grande do Sul using multi-temporal data from MODIS (Moderate Resolution Imaging Spectroradiometer) sensor on board of the Earth Observing System satellite - EOS-AM (Terra). The supervised classification algorithm Spectral Angle Mapper (SAM) was successfully applied in a multi-temporal series of pre-processed EVI images. It was verified that the areas classified as maize in the image fully agree with more extensive or continuous maize areas (>90 ha). Small or hillsides maize areas having close to shrub and wood vegetation were not detected by the classifier mainly due low spatial resolution of images. The main practical utility of maize's areas digital classification and identification using MODIS images is in its application to isolate or to complement the crop areas mapping, in order to monitor these areas, using different vegetation indices derived from high temporal and low spatial resolution images.
\end{abstract}

KEYWORDS: vegetation indices, supervised classification, orbital remote sensing.

\section{INTRODUÇÃO}

Uma das principais aplicações dos dados de sensoriamento remoto tem sido, historicamente, o mapeamento das áreas agrícolas. Trabalhos publicados, tais como os de COLLARES et al. (1993), MEDEIROS et al. (1996), MORAN et al. (1997), IPPOLITI-RAMILO (1999) e FORMAGGIO et al. (2003), referem-se a essa temática utilizando diversas metodologias e dados de satélites e sensores. A ampla gama de sensores historicamente utilizados abrange variadas

\footnotetext{
${ }^{1}$ Eng $^{\mathrm{o}}$ Cartógrafo, Doutor em Engenharia/Geoprocessamento, Pesquisador da Cargill Agrícola S.A., Av. Morumbi, 8234, Brooklin, São Paulo - SP, jose_yi@ cargill.com

${ }^{2}$ Eng $^{\mathrm{o}}$ Florestal, Doutor em Ciências Florestais/Sensoriamento Remoto, Pesquisador do Instituto Nacional de Pesquisas Espaciais INPE, yosio@ltid.inpe.br

${ }^{3}$ Estatístico, Professor Associado da Área de Geoprocessamento, Departamento de Engenharia de Transportes, Escola Politécnica, USP, jaquinta@usp.br

Recebido pelo Conselho Editorial em: 9-1-2007
}

Aprovado pelo Conselho Editorial em: 10-10-2007 
resoluções espaciais e temporais, desde o MultiSpectral Scanner (MSS), com resolução espacial aproximada de $80 \mathrm{~m}$, dos primeiros satélites Landsat, até as recentes imagens com resolução espacial nominal de $1 \mathrm{~m}$ e 0,67 $\mathrm{m}$ dos satélites IKONOS e QUICKBIRD, respectivamente. O conhecimento das áreas agrícolas e de suas dinâmicas é fundamental para seu monitoramento e constituem a base para qualquer proposta que pretenda aplicar o sensoriamento remoto num sistema objetivo de acompanhamento e de previsão das safras agrícolas.

As imagens do sensor MODIS vêm sendo utilizadas com maior frequiência em diferentes aplicações na agricultura. D'ARCO et al. (2007) utilizaram imagens NDVI derivadas do MODIS para a estimativa de áreas plantadas com arroz, e RUDORFF et al. (2007) trabalharam com uma série multitemporal de imagens MODIS para a detecção de áreas de soja, sendo ambos os trabalhos realizados em áreas agrícolas do Estado do Rio Grande do Sul.

O presente trabalho teve como proposta avaliar a identificação e o mapeamento das áreas de milho da região noroeste do Estado do Rio Grande do Sul a partir de dados multitemporais do sensor MODIS (Moderate Resolution Imaging Spectroradiometer) a bordo do satélite Earth Observing System - EOS-AM (Terra).

A detecção das áreas de milho, que é a segunda cultura em importância na região durante a safra de verão, faz parte de uma abordagem mais ampla de monitoramento das condições das lavouras agrícolas em nível regional, por meio de índices de vegetação derivados dos dados multitemporais do sensor MODIS.

\section{MATERIAL E MÉTODOS}

A área de estudo encontra-se localizada na parte noroeste do Estado do Rio Grande do Sul, limitada pelas coordenadas $27^{\circ} 00^{\prime}$ e $29^{\circ} 30^{\prime}$ de latitude sul e $50^{\circ} 30^{\prime}$ e $55^{\circ} 10^{\prime}$ de longitude oeste. Compõem a mesma 206 municípios, sendo a maioria da Mesorregião Noroeste Rio-Grandense e apenas dois municípios da Mesorregião Centro-Sul Rio-Grandense - Arroio do Tigre e Estrela Velha (IBGE, 1977; IBGE 2004). Na Figura 1, apresenta-se a localização da área de estudo nos contextos estadual e federal.

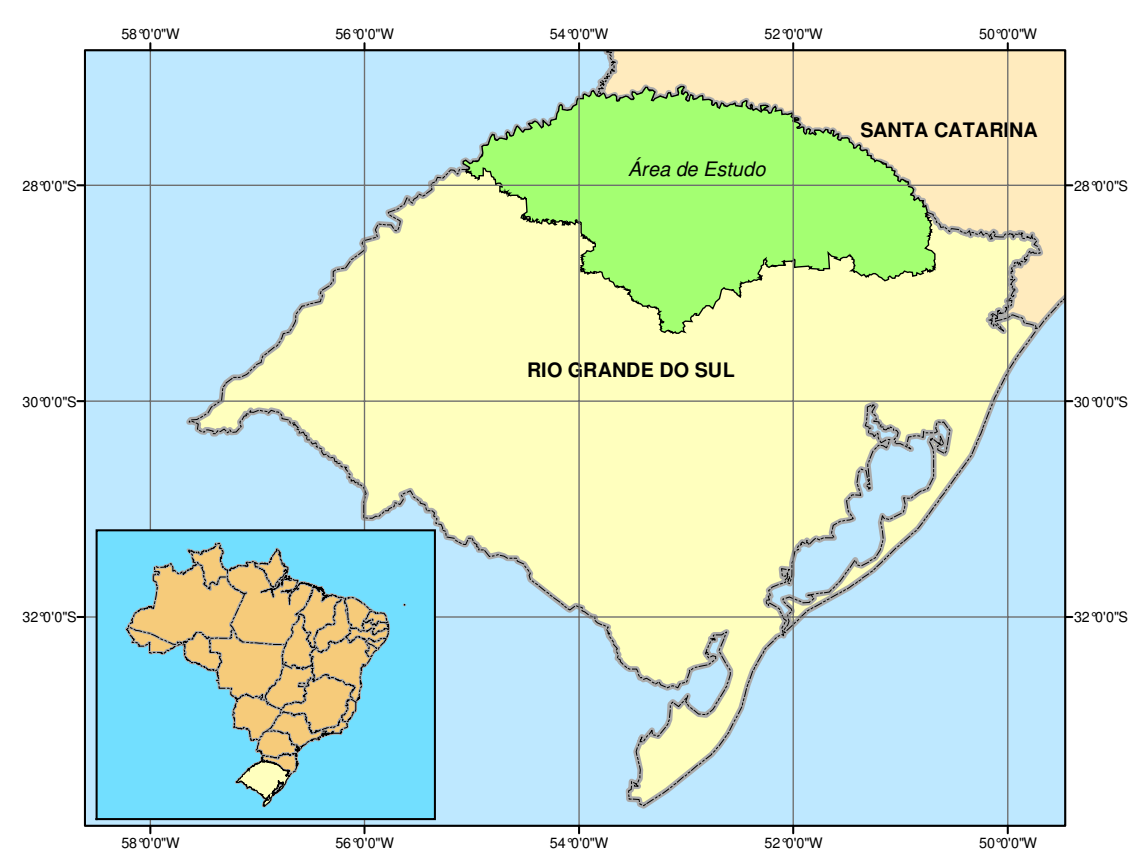

FIGURA 1. Localização da área de estudo.

No padrão de uso e ocupação do solo da região, existem dois fatores determinantes, sendo um deles físico-geográfico, representado pela associação do relevo e pelo tipo de solo, e o segundo, socioeconômico, representado pelo tamanho da propriedade. Esse último fator determina a capacidade financeira e o capital disponível pelo produtor rural (MANTELLI, 2000). 
Vale destacar o critério de tamanho da propriedade, que determina basicamente o tipo de estrutura fundiária da região. É notório o predomínio das pequenas propriedades, principalmente nos municípios mais ao norte da região, incluindo minifúndios inferiores a 10 ha, que representam $11 \%$ da superfície regional (IBGE, 1998). Nos municípios mais ao sul e a leste da área de estudo, predominam as propriedades médias, enquanto as grandes propriedades representam menos de $5 \%$ dos estabelecimentos da região. A cultura do milho encontra-se nos três tipos de propriedade, e nas pequenas seu plantio é principalmente para consumo próprio (subsistência), sendo em escala comercial nas propriedades médias e grandes.

A extensão territorial da área de estudo é de 6.099.377 ha. O predomínio da área plantada durante a safra de verão, na região corresponde à cultura da soja, com $68 \%$, é seguido pelo milho, com 27\%. Completam a lista de principais culturas da região, o feijão (4\%), a mandioca e o arroz, com pouco menos de $1 \%$. Durante a safra de inverno, as principais culturas plantadas são trigo, sorgo e aveia (IBGE, 2003).

O plantio do milho na região, de forma geral, começa no mês de setembro, bem mais cedo do que o da soja, principalmente pelo fato de essa cultura ter ciclo mais longo. Para a identificação das áreas de milho na área de estudo, foram utilizadas as composições de imagens do EVI (Enhanced Vegetation Index), disponíveis no produto MOD13Q1 - Índices de Vegetação, coleção 4, de $250 \mathrm{~m}$ de resolução espacial, correspondentes aos meses de novembro e dezembro de 2002 (LPDAC, 2004). Vale destacar que a resolução espacial de $250 \mathrm{~m}$ é a maior disponível entre os produtos derivados do sensor MODIS (YI \& QUINTANILHA, 2006; LATORRE et al., 2007).

Como se observa na Figura 2, na maior parte da área de estudo, a fase de floração do milho inicia-se já na segunda quinzena de novembro, enquanto a floração da soja se inicia apenas no final de janeiro. Com base nessa informação, e conhecendo que os maiores valores dos índices de vegetação se registram no início da floração, em dezembro a maioria das áreas de soja encontra-se ainda em desenvolvimento vegetativo (baixos valores do EVI), criou-se um arquivo multitemporal composto por três imagens (layers) EVI (Figura 3), sendo: banda 1 (B1)- corresponde à composição EVI da primeira quinzena de novembro (1 $1^{\mathrm{o}}-11$ - 16-11); banda 2 (B2)- corresponde à segunda quinzena de novembro (17-11 - 2-12), e banda 3 (B3) - corresponde à primeira quinzena de dezembro (3-12 - 18-12).

A primeira quinzena de novembro (Banda 1) foi escolhida para fazer parte do arquivo pelo fato de a maioria das áreas agrícolas a serem ocupadas por ambas as culturas (milho e soja) apresentarem ainda valores muito baixos do EVI. As áreas de milho, pelo fato de a maioria das lavouras estarem ainda em desenvolvimento vegetativo, e as áreas de soja ainda para serem plantadas e cobertas pela palha restante da colheita do trigo.

Embora as áreas de milho se encontrassem em floração no final de dezembro e no começo de janeiro, se fosse incluída a imagem EVI de final de dezembro na composição, as áreas de soja plantadas na primeira quinzena de novembro introduziriam "ruído" e contaminariam as áreas classificadas como milho.

Selecionou-se o EVI pela característica desse índice de vegetação de fornecer melhor distinção entre as áreas de culturas e do solo em relação ao NDVI (HUETE et al., 1994; YI \& SHIMABUKURO, 1999). De forma similar ao NDVI, o EVI tem vantagens e aspectos fracos, muitos deles diretamente associáveis entre ambos, como os citados em OLIVEIRA et al. (2003), em relação ao NDVI: é uma melhoria se comparado ao uso de uma só banda; é supostamente menos afetado por características topográficas; é pressuposto que normaliza as diferenças em irradiância; carrega somente parte da informação disponível nos canais originais (GOVAERTS et al., 1999), e apresenta saturação a valores relativamente baixos (EPIPHANIO et al., 1997). Os autores citam, ainda, outras características do NDVI: requer só as regiões do vermelho e do infravermelho próximo do espectro eletromagnético; é a melhor escolha para a detecção de mudanças envolvendo copa de árvores, já que enfatiza as diferenças em resposta espectral da vegetação e tem forte relação com a biomassa (ANDERSON et al., 1993; PONZONI \& SHIMABUKURO, 1998), tidas como irrelevantes para o contex to deste trabalho. 


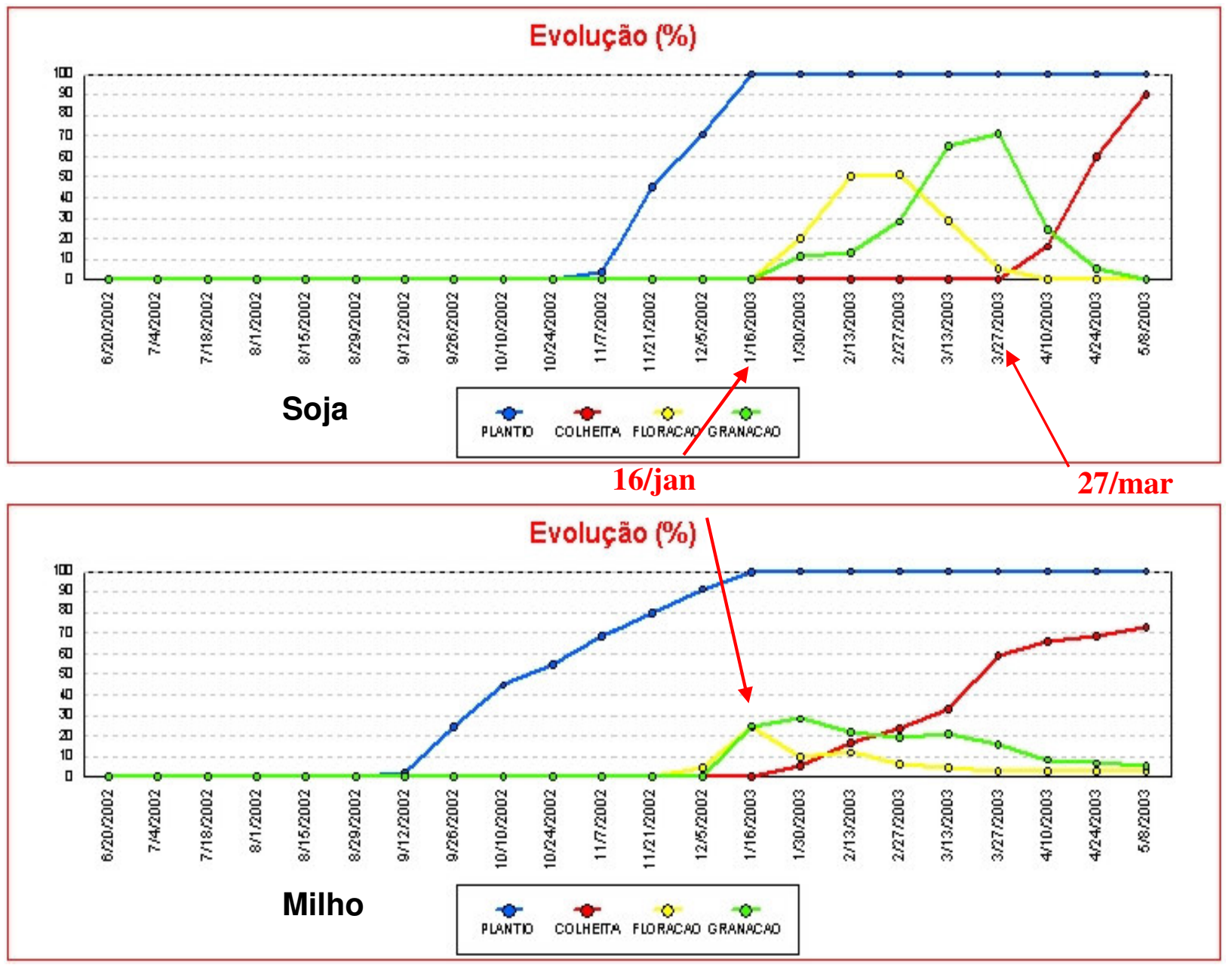

Fonte: SICRAD (2003)

FIGURA 2. Cronograma agrícola (safra 2002-2003) das principais culturas na área de estudo, mostrando as principais fases: plantio, floração, granação e colheita.

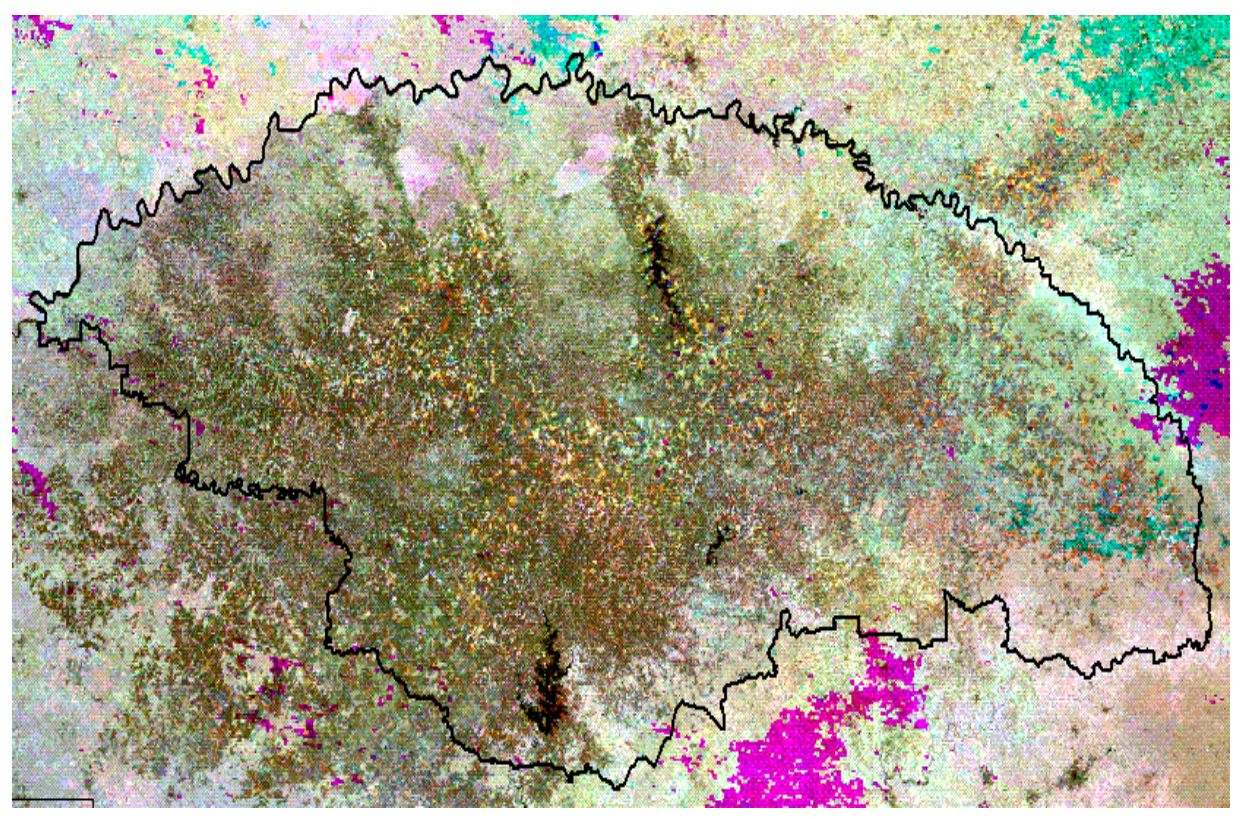

FIGURA 3. Composição R (B2) G (B3) B (B1) multitemporal das imagens EVI-MODIS do período de novembro a dezembro de 2002. 
Para a classificação digital da composição de imagens MODIS, foi utilizado o algoritmo de classificação supervisionada Spectral Angle Mapper (SAM), disponível no software de processamento de imagens ENVI, versão 4.0 (SULSOFT, 2004).

Esse algoritmo analisa os espectros de referência fornecidos (amostras, biblioteca espectral, arquivos ASCII), comparando o ângulo definido pelo vetor espectral da amostra com o do vetor correspondente ao valor espectral de cada pixel da imagem que está sendo classificada no espaço de $n$ dimensão (Figura 4), em que $n$ corresponde ao número de bandas da imagem. É assim que o algoritmo determina os pixels que pertencem a uma determinada classe (RSI, 2000).

Quanto menor a diferença entre o valor do ângulo espectral do pixel e sua referência, maior certeza de o pixel pertencer à classe mapeada. O algoritmo é particularmente eficiente, quando se têm amostras selecionadas bem definidas espectralmente, mesmo que seja um número reduzido ou apenas uma única amostra (YI, 2005).

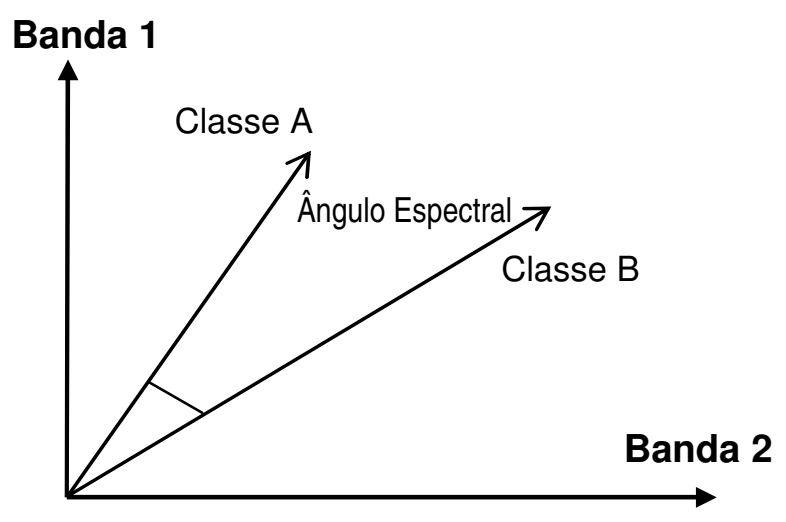

Fonte: SULSOFT (2004).

FIGURA 4. Exemplo de Spectral Angle Mapper bidimensional.

As amostras para a classificação foram selecionadas a partir da própria imagem, utilizando-se das composições $R(B 3) \mathrm{G}(\mathrm{B} 2) \mathrm{B}(\mathrm{B} 1)$ e $\mathrm{R}(\mathrm{B} 2) \mathrm{G}(\mathrm{B} 3) \mathrm{B}(\mathrm{B} 1)$ escolhidas pelo fato de as bandas 2 e 3, com altos valores de EVI, destacarem melhor as áreas de milho. Os resultados da classificação das áreas de milho foram editados manualmente para eliminar áreas de ruído na imagem classificada e pixels isolados classificados.

\section{RESULTADOS E DISCUSSÃO}

Na Figura 5, apresenta-se detalhe da composição RGB multitemporal do EVI mostrada anteriormente, na qual se observam as áreas de milho na região de estudo em amarelo e laranjaclaro. No canal R (vermelho), mostra-se a imagem EVI correspondente ao período de 17 de novembro a 2 de dezembro; no canal G (verde), mostra-se o EVI correspondente ao período de 3 de dezembro a 18 de dezembro, e no canal B (azul), mostra-se o EVI correspondente ao período de $1^{\underline{0}}$ a 16 de novembro de 2002. No detalhe (círculo verde), mostra-se exemplo da área selecionada como amostra para a classificação supervisionada executada.

A partir da análise dessa imagem à luz do gráfico da Figura 2, pode-se depreender que, na região de estudo, no fim do mês de dezembro, praticamente $100 \%$ das áreas de milho já foram plantadas, sendo boa parte delas (aproximadamente 30\%) em floração. Como os maiores valores do índice são registrados precisamente no período prévio à floração, podem-se observar, em amarelo, as áreas de milho, pois são altos os valores do EVI nos canais R e G (17-nov. a 18-dez.). Como a formação da cor acontece pelo método aditivo, $\mathrm{R}+\mathrm{G}$ é igual a $\mathrm{Y}$ (amarelo). 


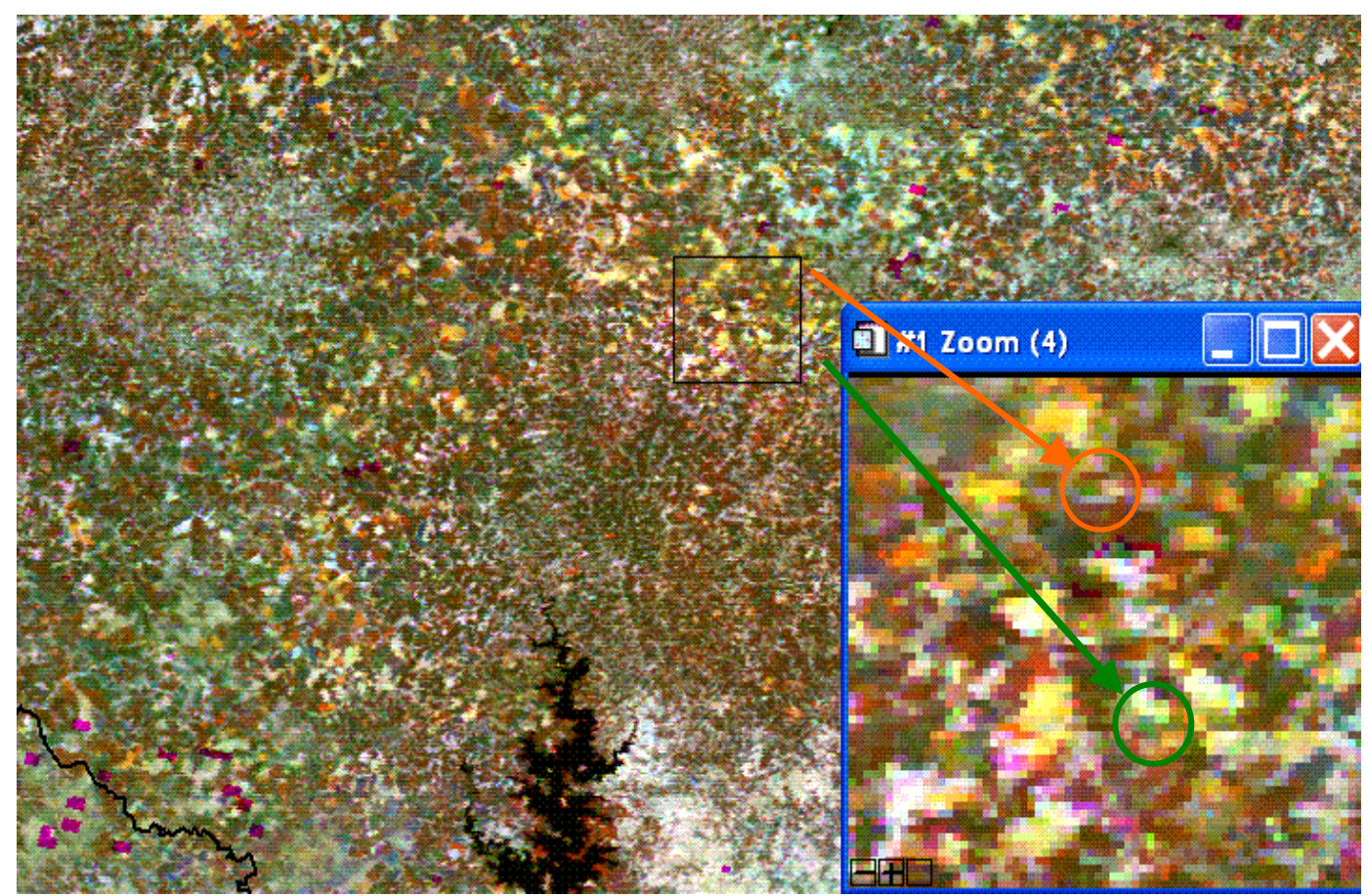

FIGURA 5. Detalhe da composição multitemporal RGB de imagens EVI; em amarelo, as áreas de milho. Na ampliação (zoom), destacam-se as áreas amostradas.

O exposto acima pode ser perfeitamente verificado na análise da Figura 6. No perfil espectral de uma das áreas de milho, o valor máximo da curva é atingido na banda 4, correspondente ao período de 3 a 18 de dezembro. Para a mesma área, os valores correspondentes à banda 5 (19 - 31 de dezembro) ainda são altos, mas já decrescentes. Enquanto se pode observar que, na curva para outra área colhida em fins de outubro (provavelmente trigo) e plantada em novembro (com soja), o valor do EVI mostra-se em ligeiro crescimento na segunda quinzena de dezembro. As áreas amostradas pelo perfil espectral aparecem em destaque na Figura 5 (janela de zoom), em amarelo e verde-escuro, respectivamente.

A classificação supervisionada final das áreas de milho obtida por meio do algoritmo de Mapeamento de Ângulo Espectral $(S A M)$ foi executada com um ângulo espectral máximo igual a 0,12 radiano. Esse valor foi selecionado após serem testados diferentes valores angulares, maiores e menores, pelo fato de ser o de melhor resultado na delimitação das áreas de milho identificadas visualmente na imagem. Isso significa que 0,12 radiano é o valor angular máximo aceitável entre o vetor definido pelo espectro de referência (amostra da classe) e o vetor definido pelo valor espectral do pixel que está sendo classificado. Pixels com valores maiores que 0,12 radiano em relação à referência não foram classificados como milho. $\mathrm{O}$ resultado final da classificação das áreas de milho é mostrado na Figura 7.

A validade do método aditivo RGB com as imagens multitemporais do EVI do MODIS para a identificação de áreas de milho foi avaliada durante percurso de três dias realizado na região de estudo, em janeiro de 2004. Devido ao fato de a viagem ter sido realizada no ano-safra seguinte aos processamentos, a abordagem foi realizada com imagem MODIS composta pela mesma metodologia, com dados EVI de novembro e dezembro de 2003. 


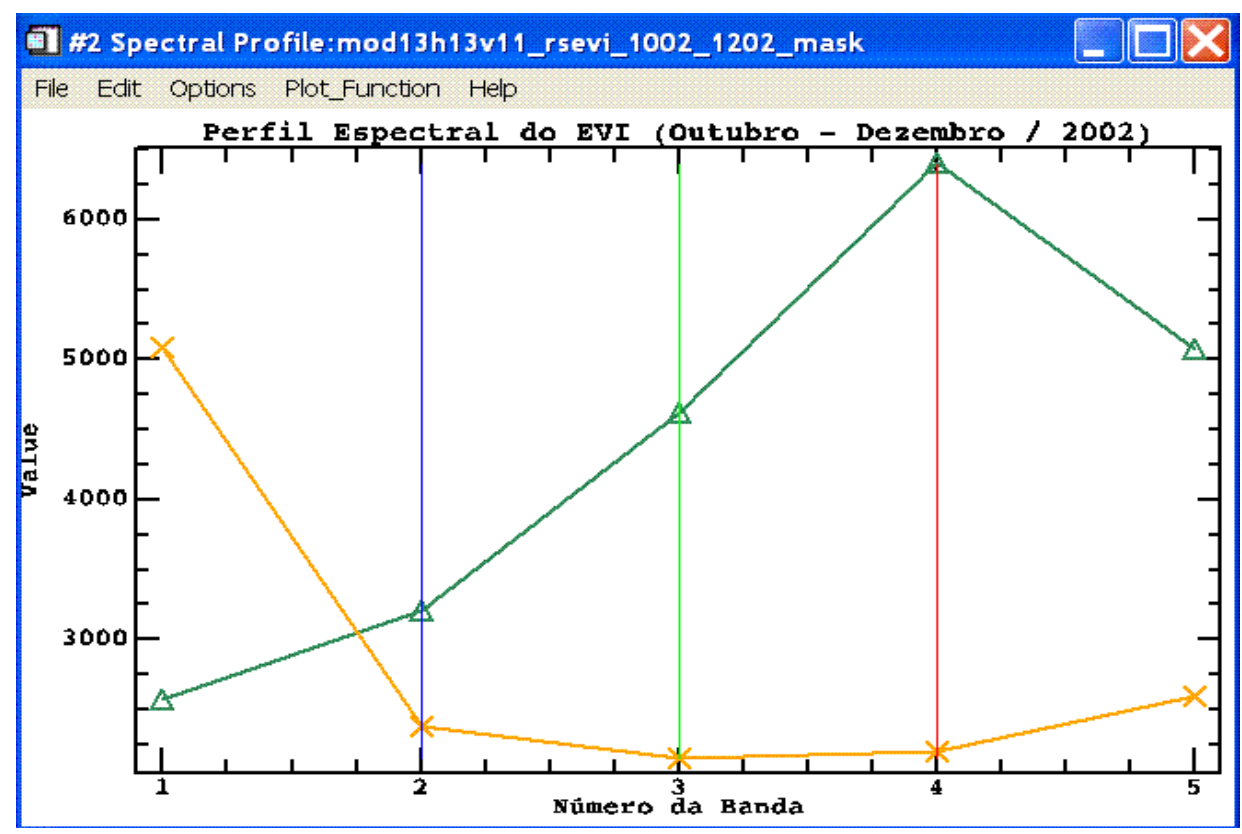

FIGURA 6. Perfis espectrais do arquivo multitemporal de imagens EVI para área de milho (em verde) e área colhida de trigo com plantio recente de soja (em laranja). Banda 1 (16 -31 out.), banda 2 ( $1^{\mathrm{o}}-16$ nov.), banda 3 (17 nov.-2 dez.), banda 4 (3-18 dez.), banda 5 (19-31 dez.).

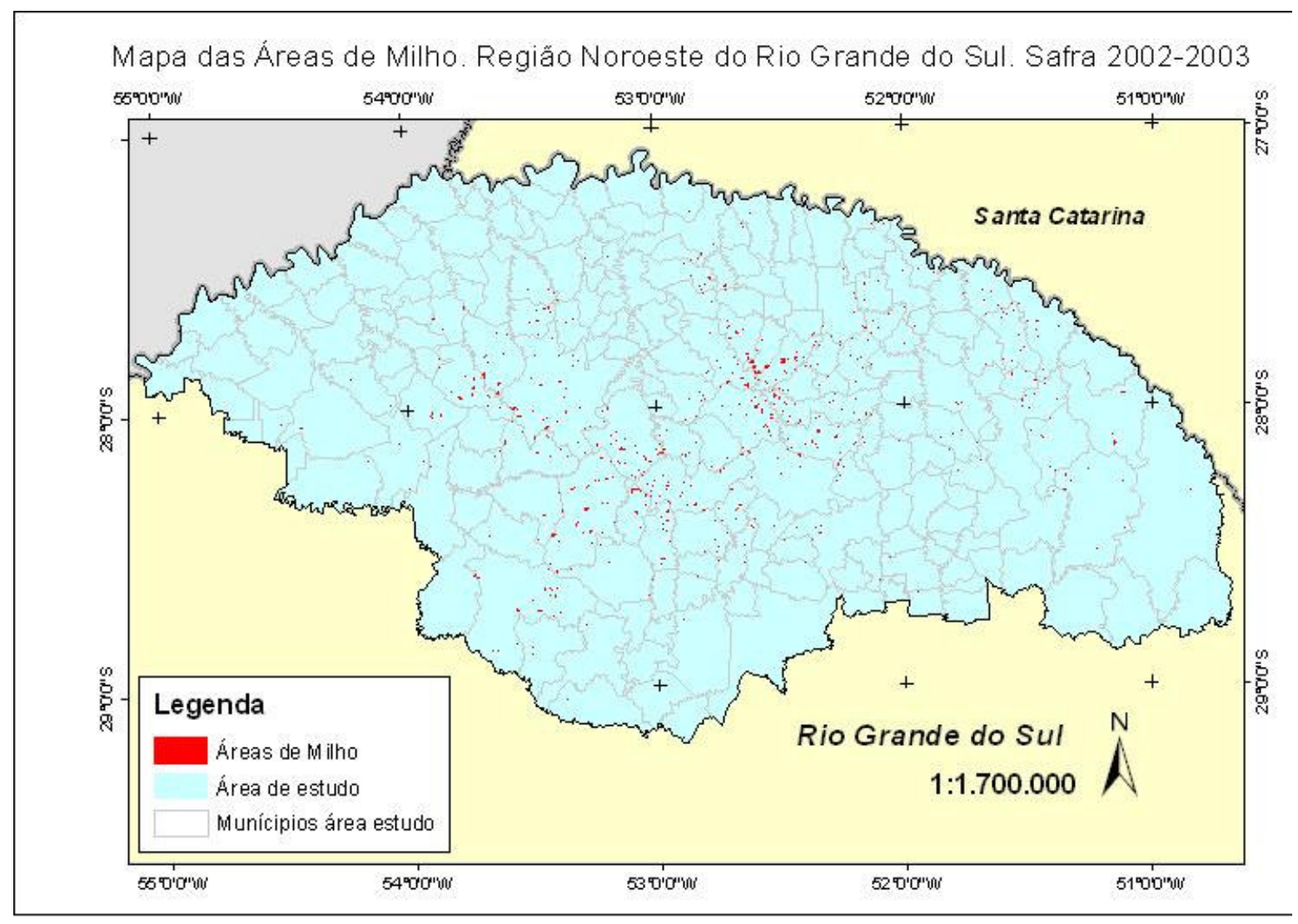

FIGURA 7. Resultado da classificação mostrando em vermelho as áreas de milho (dezembro, 2002) na região de estudo.

Verificou-se que as áreas classificadas como milho na imagem coincidiam plenamente com áreas mais extensas (>90 ha) ou contínuas (Figura 8). Pode-se comprovar que muitas lavouras de milho da região, que ocupam áreas de menor extensão, ou encontram-se localizadas em encostas de 
morros ao lado de vegetação arbórea, fazem parte de pixels de mistura espectral e não são detectadas pelo classificador devido à limitada resolução espacial das imagens MODIS (Figura 9).

Acredita-se que, se a resolução espacial dos dados fosse de, pelo menos, $100 \mathrm{~m}$, muitas áreas de milho de menor extensão poderiam perfeitamente ser detectadas durante a classificação.

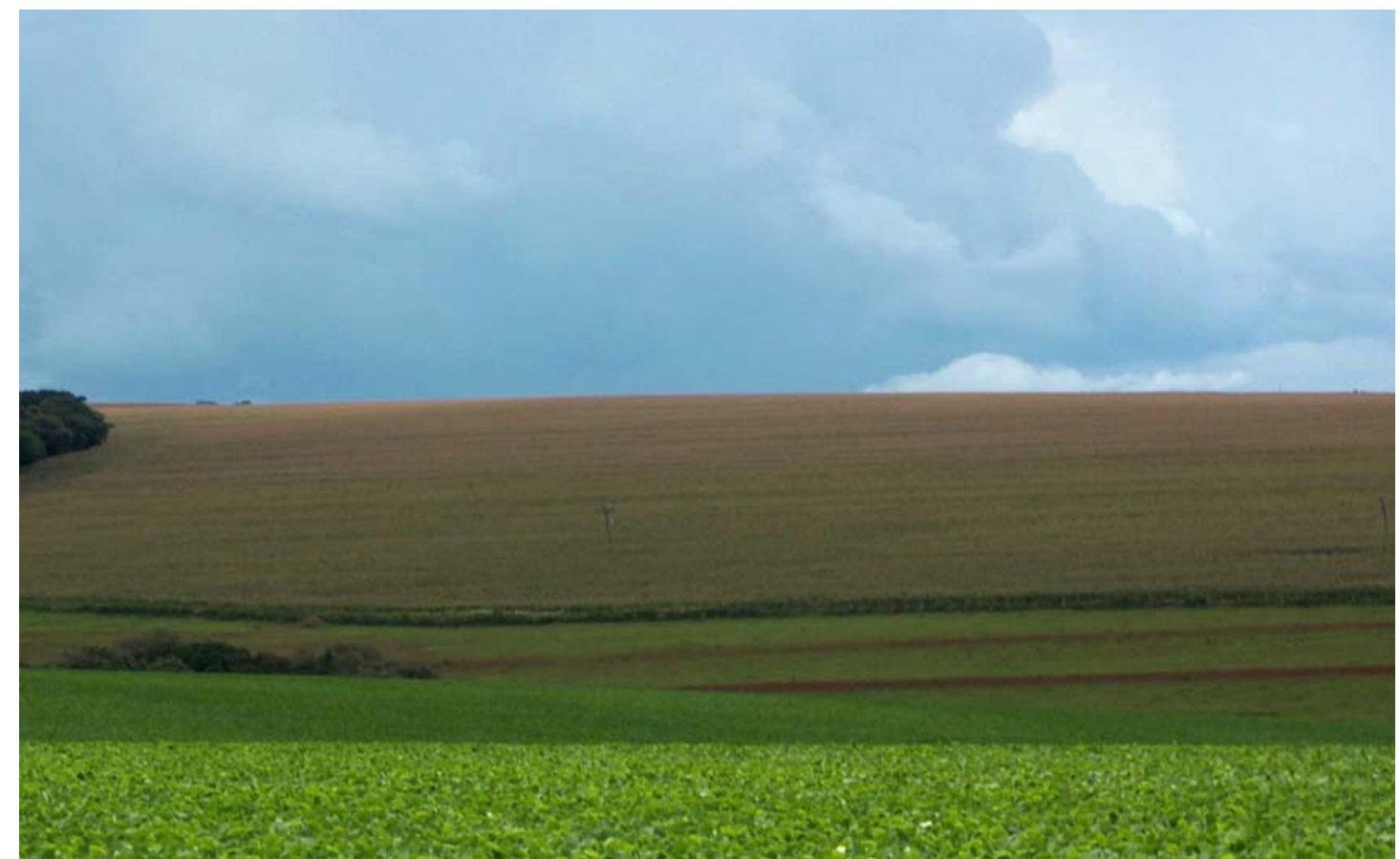

FIGURA 8. Exemplo de área de milho no município de Erechim, detectada e classificada na imagem MODIS.

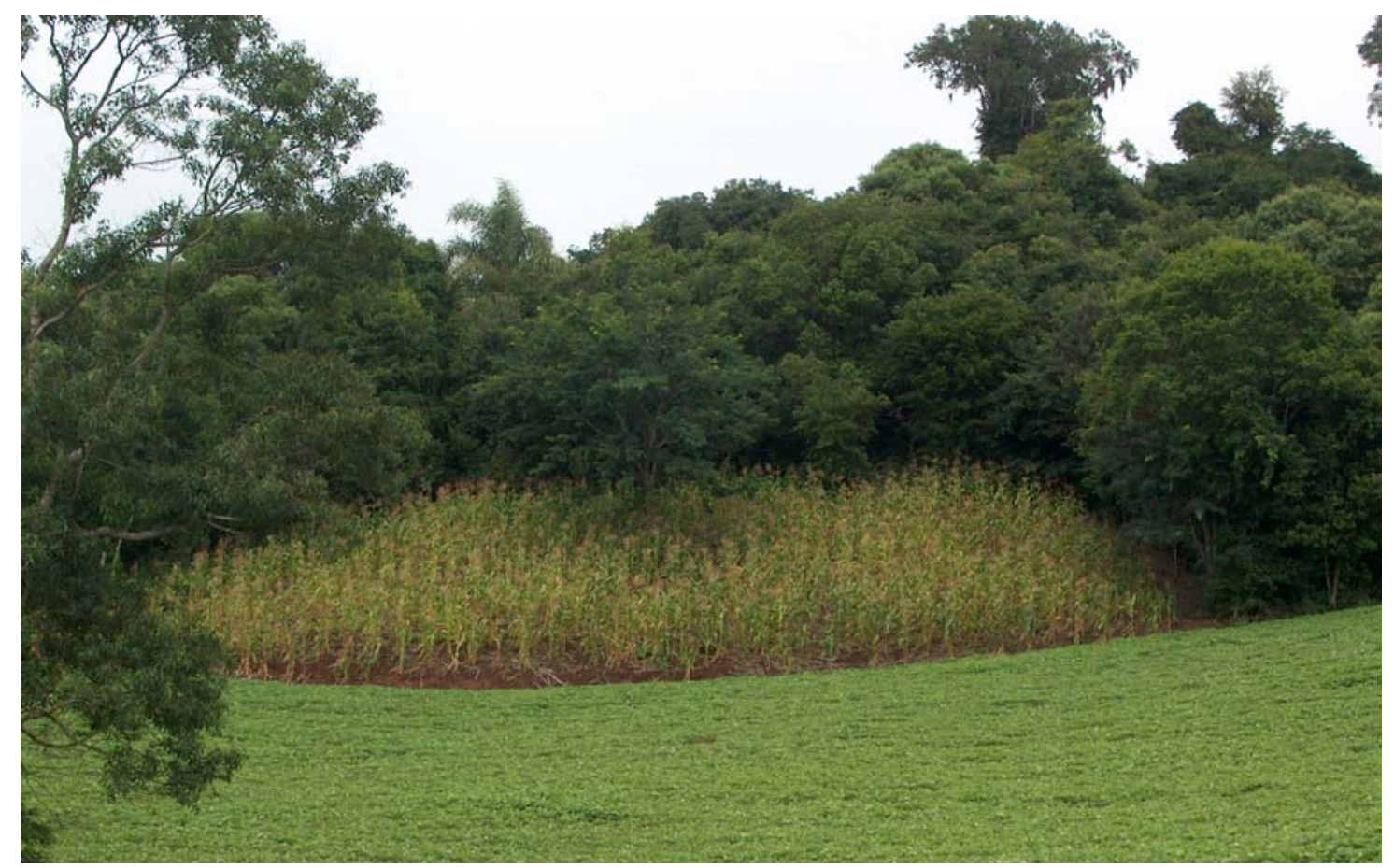

FIGURA 9. Exemplo de área de milho não-identificada na imagem MODIS.

A maior utilidade prática da identificação e da classificação digital de áreas de milho, a partir de imagens MODIS, na região de estudo, está na sua aplicação para isolar ou complementar o mapeamento das áreas agrícolas visando ao seu monitoramento a partir de índices de vegetação, 
derivados de imagens de baixa resolução espacial, porém com alta resolução temporal, como as provenientes do sensor MODIS.

Essa abordagem metodológica pode ser aplicada de forma operacional a baixo custo, devido à cobertura global dos dados MODIS e ao fato de os mesmos estarem sendo disponibilizados pela NASA em tempo quase real e de forma gratuita na Internet.

A resolução espacial de apenas $250 \mathrm{~m}$ das imagens MODIS, em conjunto com o padrão de ocupação e distribuição das lavouras de milho na região de estudo, constitui a principal limitação objetiva para o mapeamento preciso e confiável da cultura. Isso impossibilita o uso das composições de imagens MODIS para qualquer avaliação quantitativa de área plantada de milho, pelo menos, em regiões com semelhante padrão de uso e ocupação do solo.

\section{CONCLUSÕES}

A utilização de composição multitemporal RGB de três imagens EVI do produto MOD13Q1, correspondentes ao período novembro-dezembro, mostrou-se eficiente para identificar e mapear parcialmente as áreas de milho, na região noroeste do Estado do Rio Grande do Sul.

A classificação digital supervisionada, executada utilizando o algoritmo do Mapeador de Ângulo Espectral $(S A M)$, identificou com êxito as áreas extensas de milho ou contínuas com superfície média de aproximadamente 90 ha ou maiores.

O critério da abordagem multitemporal utilizando os dados MODIS reafirmou o valor da alta resolução temporal no mapeamento de um fenômeno altamente dinâmico como a agricultura e, em particular, as lavouras de ciclo curto. Isso reforça o critério do altíssimo potencial de aplicação na agricultura de outros sensores remotos que possuem melhor resolução espacial, como o AWFIS (Advanced Wide Field Sensor), a bordo do satélite indiano IRS-P6, com pixel de $60 \mathrm{~m}$, além de alta resolução temporal.

\section{AGRADECIMENTOS}

À Escola Politécnica da Universidade de São Paulo - EPUSP, ao Conselho Nacional de Desenvolvimento Científico e Tecnológico - CNPq, ao Instituto Nacional de Pesquisas Espaciais INPE e à Cargill Agrícola S.A.

\section{REFERÊNCIAS}

ANDERSON, G.L.; HANSON, J.D.; HAAS, R.H. Evaluating Landsat Thematic Mapper derived vegetation indices for estimating above-ground biomass on semiarid rangelands. Remote Sensing of Environment, New York, v.45, p.165-75, 1993.

COLLARES, J.E.R.; LAURIA, C.A.; CARRILHO, M.M. Pesquisa de previsão e acompanhamento de safras baseada em painéis de amostras de áreas. In: SIMPÓSIO BRASILEIRO DE

SENSORIAMENTO REMOTO, 7., Curitiba, 1993. Anais... São José dos Campos: INPE, 1993. v.1, p. 450-3.

D’ARCO, E.; RUDORFF, B.F.T.; RIZZI, R. Índice de Vegetação para estimativa de área plantada com arroz irrigado. In: RUDORFF, B.F.T.; SHIMABUKURO, Y.E.; CEBALLOS, J. C. (Eds.). $O$ sensor MODIS e suas aplicações ambientais no Brasil. São José dos Campos: Ed. Bookimage, 2007. p.123-131.

EPIPHANIO, J.C.N.; ALMEIDA JÚNIOR, A.C. DE; FORMAGGIO, A.R. Wheat development evaluated by remote sensing using two vegetation indices. Anais da Academia Brasileira de Ciências, v.69, n.4, p.471-8, 1997.

FORMAGGIO, A.R.; MOURA, V.; EPIPHANIO, J.C.N.; SILVA, H.R.; FIORIO, P.R.; CAMPOS, R.C. Dados TM/Landsat na estimativa de áreas destinadas a culturas de verão no Estado de São 
Paulo. In: SIMPÓSIO BRASILEIRO DE SENSORIAMENTO REMOTO, 11., 2003, Belo Horizonte. Anais... São Paulo: [s.n], 2003. 1 CD-ROM.

GOVAERTS, Y.M.; VERSTRAETE, M.M; PINTY, B.; GOBRON, N. Designing optimal spectral indices: a feasibility and proof of concept study. International Journal of Remote Sensing, London, v.20, n.9, p.1853-73, 1999.

HUETE, A.R.; JUSTICE, C.; LIU, H. Development of vegetation and soil indices for MODISEOS. Remote Sensing of Environment, New York, v.49, p.224-34, 1994.

IBGE. INSTITUTO BRASILEIRO DE GEOGRAFIA E ESTATÍSTICA. Superintendência de estudos geográficos e socioeconômicos. Departamento de Geografia. Geografia do Brasil. v.5, Rio de Janeiro, 1977.

IBGE. INSTITUTO BRASILEIRO DE GEOGRAFIA E ESTATÍSTICA. Levantamento sistemático da produção agrícola. LSPA 2003. Disponível em: http://www.ibge.gov.br. Acesso em: 15 jul. 2004.

IBGE. INSTITUTO BRASILEIRO DE GEOGRAFIA E ESTATÍSTICA. Malha municipal digital do Brasil. Situação em 2001. v.2. Projeção Policônica. Cód. 2488. Rio de Janeiro, 2004. 1 CDROM. Disponível em: http://www.ibge.gov.br/lojavirtual/lojavirtual.php?midia=CDPU\&tit=12\&id _subcat $1=10 \& i d \_s u b c a t 2=0 \& i d \_s u b c a t 3=0 \&$ paginaatual=2\&letra $=$. Acesso em: 20 dez. 2004.

IBGE. INSTITUTO BRASILEIRO DE GEOGRAFIA E ESTATÍSTICA. Censo Agropecuário do Rio Grande do Sul - 1995. Rio de Janeiro, 1998.

IPPOLITI-RAMILO, G.A. Imagens TM/Landsat-5 da época de pré-plantio para a previsão da área de culturas de verão. 1999. 183 f. Dissertação (Mestrado em Sensoriamento Remoto) Divisão de Sensoriamento Remoto, Instituto Nacional de Pesquisas Espaciais, São José dos Campos, 1999.

LATORRE, M.L.; SHIMABUKURO, Y.E.; ANDERSON, L.O. Produtos para ecossistemas terrestres (MODLAND). In: RUDORFF, B.F.T.; SHIMABUKURO, Y. E.; CEBALLOS, J.C. (Eds.): O sensor MODIS e suas aplicações ambientais no Brasil, São José dos Campos: Ed. Bookimage, p. 23 - 36, 2007.

LPDAC. LAND PROCESSES DISTRIBUTE ARCHIVE CENTER. MODIS DATA PRODUCTS. Disponível em: <http://edcdaac.usgs.gov/modis/dataproducts.asp> .Acesso em: 15 jul. 2004.

MANTELLI, J. Evolução e tendências do setor agrário na região noroeste do Estado de Rio Grande do Sul: uma proposta de análise. 2000. 202 f. Tese (Doutorado em Geografia Humana) Faculdade de Filosofia Letras e Ciências Humanas, Departamento de Geografia, Universidade de São Paulo, São Paulo, 2000.

MEDEIROS, A.M.P.; RUDORFF, B.F.T.; SHIMABUKURO, Y.E. Imagens Landsat na estimativa de áreas de cana-de-açúcar, milho e soja. In: SIMPÓSIO BRASILEIRO DE SENSORIAMENTO REMOTO, 8., Salvador, 1996. Anais... São Paulo: [s.n], 1996. 1 CD-ROM.

MORAN, M.S.; MAAS, S.J.; BARNES, E.M. Opportunities and limitations for image-based remote sensing in precision crop management. Remote Sensing of Environment, New York, v.61, p.319-46, 1997.

OLIVEIRA, Y.M.M.; BURLEY J.; DAWSON T.; PACKER, M. Detecção de mudanças em área com floresta ombrófila mista (floresta de araucária) - abordagem usando imagens diferença. In: SIMPÓSIO BRASILEIRO DE SENSORIAMENTO REMOTO, 11., 2003, Belo Horizonte. Anais... São Paulo: [s.n], 2003. p.2835-43.

PONZONI, F.J.; SHIMABUKURO, Y.E. Relação entre índices de vegetação (NDVI e SAVI) e parâmetros biométricos de plantios de Eucalyptus sp. Revista Árvore, Viçosa - MG, v.22, n.3, p.337-66, 1998. 
RSI, RESEARCH SYSTEMS. ENVI User's Guide. ENVI Version 3.4. Boulder, CO., 2000. 930 p.

RUDORFF, C.M.; SUGAWARA, L.M.; VIEIRA, C.A.O;; RIZZI, R. Classificação de soja pelo método de superfícies de resposta espectro-temporal. In: RUDORFF, B.F.T.; SHIMABUKURO, Y.E.; CEBALLOS, J.C. (Eds.). O sensor MODIS e suas aplicações ambientais no Brasil. São José dos Campos: Ed. Bookimage, 2007. p.111-21.

SICRAD. SISTEMA DE COLETA, RECUPERAÇÃO E ANÁLISE DE DADOS. Departamento de Análise Agroeconômica. Complexo Soja. Cargill Agrícola S.A. Disponível em: intranet Cargill Agrícola. Acesso em: 21 jan. 2003.

SULSOFT PROCESSAMENTO DE DADOS. Guia do ENVI em português. Versão 4.0. Porto Alegre. Disponível em: http://www.envi.com.br. Acesso em: 15 nov. 2004.

YI, J.L.R.; QUINTANILHA, J.A. O futuro do MODIS no Sistema de Observação da Terra. In: RUDORFF, B.F.T.; SHIMABUKURO, Y.E.; CEBALLOS, J.C. (Eds.): O sensor MODIS e suas aplicações ambientais no Brasil. São José dos Campos: Ed. Bookimage, 2006. p.89-94.

YI, J.L.R.; SHIMABUKURO, Y.E. Mapeamento e monitoramento da vegetação do Estado do Mato Grosso através de imagens AVHRR-NOAA. Revista Árvore, Viçosa - MG, v.23, n.1, p.93$102,1999$.

YI, J.L.R. Dados do sistema sensor MODIS-TERRA para avaliação e monitoramento de áreas agrícolas na Região Sul do Brasil. 2005. 181 f. Tese (Doutorado em Engenharia de Transportes) Universidade de São Paulo, São Paulo, 2005. 